\title{
IMPROVING STUDENT LEARNING WITH A MORE EFFECTIVE TEACHING ENVIRONMENT
}

\author{
Daniel Davis \\ Associate Professor \\ Department of Architecture \\ College of Engineering, Technology, and Architecture \\ University of Hartford \\ Phone: 860.768.4094 / Fax 860.768.5074 \\ ddavis@hartford.edu
}

\begin{abstract}
This paper attempted to consider how a quality school environment enhances, even improves, attitudes and achievements, and how a well-designed university facility is one that carefully integrates the curriculum and the educational environment. While the evaluation of the impact of facilities on education has long been a concern of many educators, quantifying the impact of it is extremely difficult to measure. While more study is necessary, it is possible to establish a set of design principles or concepts that foster better teaching and learning environments. This leads to what could be the very first principle in school design:

- The space must be designed to foster and enhance learning and not impair or hinder it. In fact, the school facility must be conceived as a teaching and learning instrument in its own right.

These environments also help students to become more independent and responsible for their own learning. A well-equipped college classroom supports the curriculum and the teachers by acting as a regenerative research and resource center. Probably the most important issue that school designers and educators must understand is how the physical environment relates to and supports the teaching and learning process. Teaching facilities must be nurturing, healthy, illuminating, exciting places to live, learn, and prepare for the future.
\end{abstract}

\section{Design Principles}

Almost everything about the design of a university facility flows from the principle mentioned above. However, there are at least three other closely related principles that also shape many aspects of school facility design:

口 Every aspect of a school facility should be program-driven, or as architect Louis Sullivan said "form follows function". 
- The facility should be an expression of the values and goals of the university program that uses it.

a The facility should strive to be flexible enough to accommodate the educational changes that will certainly occur in the future.

These are the primary design principles. Let us now explore how these principles can be applied to conceptual aspects of school design.

\section{Project-based Learning Environments}

Classrooms can no longer be thought of in the traditional sense as having an instructor at the blackboard in the front of the room with students at desks and chairs in regimented rows. Ideally, the college classroom needs total flexibility. But that is hard to achieve while still bringing utilities (like power, data, gas and water) to students. Perhaps future classrooms will need to be much larger, to allow for traditional instructional areas surrounded by clusters of project areas all in one room. [1]

There is an emerging trend towards larger better-equipped college classrooms. Over the past few decades students have been taught on a discipline-by-discipline model, separate periods for separate courses. Typically, lectures on these courses were centered on a textbook. Today there is evidence of a shift toward multidisciplinary learning and multi-source instruction.

Increasingly, learning is centered on projects. Individuals and/or teams of students attack a problem using a multidisciplinary approach and any number of resources. In these new spaces, students would be encouraged to discuss, analyze, compare, negotiate, hypothesize, and problem solve through group activity. This change in methodology should influence the design of universities and their classrooms.

So if multidisciplinary, multi-source instruction is a good thing, then perhaps we may well see fewer single purpose rooms such as the dedicated biology lab or computer lab. Instead, the general college classroom will be outfitted to afford student teams all of the necessary tools immediately at hand. Indeed, the discrete computer lab is already beginning to vanish, because students need less instruction in simple computer skills and teachers prefer to have computers in their primary classrooms.

Multidisciplinary, multi-source instruction may mean that teachers will move from class to class while students more or less stay put. In other words, students studying a multifaceted project in a college classroom, with all resources at hand, will have specialist teachers visit the classroom to teach the various disciplines involved. Closest to this concept are the cluster teaching methodologies used in middle schools. In kindergarten, this model has been used for years, by creating activity centers within the classroom and with art and music teachers visiting the classroom. [2]

\section{A Place of Their Own}

I believe that one of the fundamental premises of university design is that it: 
- should provide an appropriate transitional environment between the controlled atmosphere of high school and the larger, more self-directed environment of the corporate world.

The university setting must play a part in helping young adults deal with the great intellectual, emotional, physical, and social changes that occur during early adulthood. In general, this means that school design must foster the "academic village" or "communities of learning" concept, which in turn requires that the building incorporate strategies for "making the big school feel small." Usually, the desired intimacy of scale and the strong sense of group identification that ensues when students feel that they have "a place of their own" within the larger school environment is achieved through some sort of team arrangement. This can be done in many ways. The individual team area and its relation to its neighboring teams and to the school as a whole, needs to be closely tied to and grow out of the particular model of learning that the school's stakeholders have decided to adopt.

\section{A Flexible Facility Built for Change}

Educational reform is conceived not as a "goal" but as an ongoing process. Because of this, it is not just likely that university education will change during the coming years; it is a certitude. The school facility of the future, therefore, must go far beyond grudgingly accommodating change. They must be built for the changes that will definitely occur. Moreover, flexibility is not just something that will be needed in the future. A high degree of flexibility is required right now, to accommodate all the non-standardized aspects of university education that are already in place, including:

- Exploratory, project-based learning where students "learn to learn" by engaging in a wide range of activities

- Outcome assessment, capstone programs and portfolios

- Teaming and group decision-making, with teachers acting as facilitators or "coaches"

- An ever-shifting combination of individual and small- and large-group learning experiences

Maximizing flexibility requires paying scrupulous attention to every component of facility design, including things like classroom fixtures, furniture, equipment, and storage spaces. Flexibility should be the most important criterion in furniture selection. It is obvious that the rigid grids of desks and chairs that characterized the traditional classroom are totally inappropriate for a university approach that emphasizes constantly changing patterns of interaction, each driven by the nature of the subject being explored and the kind of project being undertaken. Adequate storage is also an issue in school design. Usually, attention focuses on the amount of storage or the size of various kinds of storage spaces. These will always remain important considerations, but an equal amount of attention has to be paid to the flexibility of storage and to how well it matches the kinds of educational activities it is meant to support

It may seem odd to claim that design should positively interact with the methods of assessment used by a school, but it is true. For example, if a university employs a physical "portfolio" method for assessing students' progress, it is very important that there be storage spaces ample enough to hold the projects that students produce and accumulate over time. These might take the form of easily accessible, specially designed shelves or cabinets capable of holding both the two- and three-dimensional "products" that students create. 
Creating a truly flexible design that welcomes change can require a delicate balance. On the one hand, flexible design runs counter to the rigidly institutional design of yesterday's schools. A genuinely flexible facility is one that addresses the possibility that the building may be put to a different use at some point in the future if a department's needs change. Today, it is not uncommon to see space being renovated to serve another entirely different academic purpose.

\section{"Bumping into Things"}

Students should bump into things. This does not mean that they should physically injure themselves, rather that the school environment should give them plenty of opportunity to encounter and explore the world around them. Students are naturally resourceful, curious, competent, and imaginative, and they want to interact and communicate with others. They can best create meaning and make sense of their world in rich, complex environments that support varied, sustained, and changing relationships between people, the world of experience, ideas and the many ways of expressing ideas rather than from simplified lessons and/or learning environments. [3] They are most likely to learn from "peak experiences" that are discrepant, surprising, active, and have a strong emotional element. A handful of profound learning experiences requiring analysis and synthesis are vastly more lasting and important to students than weeks spent skimming reams of superficial facts for memorization and recall.

Translating these attributes of powerful, effective learning experiences into architectural terms requires creativity and even a bit of humility on the part of the designer. But in early 2002, I had an experience that led me to do some serious thinking about spaces designed for hands-on, exploratory learning. I happened to visit the new Aerospace Research Laboratory at the Massachusetts Institute of Technology, in Cambridge. What especially impressed me about the facility were the studios where engineering students gather to build, present, and critique projects. Unlike other educational architecture that I had seen, these laboratories or studios were intentionally designed in a non-precious manner. They were, in other words, real, hands-on workplaces - easy to mess around in and difficult to mess up in the sense of causing permanent damage to the facility.

I think that this is an idea that is widely applicable in educational environments on all levels; perhaps especially at the university level, where such strong emphasis is put on exploratory, project-driven learning. Why not design at least some learning spaces in this intentionally nonprecious way? This does not mean that design does not have to be meticulous, because it is utterly important that such spaces provide everything that is needed to accomplish the projects that will happen there. It is also crucial that such spaces be easy to clean and that they be organized in such a way that it is not necessary to clean up everything at the end of a given session if the project is not yet finished. It is also important that storage be adequate and appropriate for the work that goes on. In addition, it is critical that the furniture and finishes in these spaces be especially durable, to withstand the wear and tear of real, hands-on work.

Based on what I saw at MIT and on conversations I have had with other educators I feel strongly that all new university teaching facilities should incorporate one or more such "non-precious" spaces where students can really "work with stuff." Such laboratory/studio spaces might be 
totally generic in character or be specifically devoted to one kind of use and be shared by various teams on a rotating basis throughout the semester.

\section{Built to Last}

I have just mentioned the importance of durability in the selection of furniture and finishes for "non-precious" laboratory/studio spaces, but really, durability should be a primary criterion in choosing furniture and finishes for the school as a whole. Durable finishes not only look better longer, but there is a significant security-related value in selecting especially durable materials because they are relatively impervious to vandalism damage.

Especially durable materials tend to be more expensive in terms of first costs than do lessdurable alternatives. This is the wrong place to be penny-wise, since it is often the case that durable materials will pay for themselves many times over during the life of the building. They are easier to maintain and do not have to be replaced as often. Take the example of flooring. The installation costs of terrazzo floors are significantly higher than those of vinyl composition tile flooring. However terrazzo is likely to last the life of the building; with a minimum amount of maintenance, it continues to look handsome; and it is very difficult to damage. On the other hand, vinyl wears out and begins to look tired more quickly; and it is labor-intensive to maintain. The lesson is not just that "you get what you pay for"; it is that you will continue to pay (and pay) if you choose the less durable and seemingly less costly option.

Before making any decision on a particular finish, it is essential to understand its longevity and maintenance requirements and to predict the amount of wear and tear that a particular finish is likely to be subjected. Gypsum wallboard may be an appropriate wall material in some corridors; while concrete masonry units may better serve other corridor applications. It should also be noted, that durability is not the only criterion guiding the selection of materials; acoustical properties or moisture resistance may trump durability in certain applications.

\section{"Invisible" Technology}

A university facility's relationship to educational technology has matured far beyond the point when the computer station was the showpiece of the college classroom. Technology can assist and enhance learning and various devices and systems will become a more essential component in the learning process, it is time to think of technology as "just another tool" in an educator's toolbox, and that school buildings be designed to seamlessly integrate technology.

As a design concept, this means avoiding "over-celebrating" or overemphasizing technology, even as we create spaces that flexibly accommodate many different kinds of it. Technology, in other words, should be "invisible": always there, always ready to use when needed, but just a plank in the stage on which learning takes place. Considering our enthusiasm for educational technologies we should not lose sight of the fact that it is the student not the electronic device or the technological system that is the major player here. It is the relationship between students and teachers and other students that should to be the primary focus. 
One cautionary note needs to be voiced about the future of educational technology and its potential impact on the design of school buildings. Expanding opportunities for "virtual learning" will have a profound impact on school design. There has been much speculation about how certain kinds of computer and internet-based learning activities can be performed anywhere. Some even feel that the school buildings themselves might someday become "dinosaurs" and a no-longer-necessary artifact of education's past.

My caution is a simple one: that we should not allow our enthusiasm for virtual learning, which has some very real uses, lead us to forget that hands-on physical and social experiences are equally legitimate and important aspects of education. In a society where decisions are made democratically and where work is increasingly team-based, the school building will always be necessary as the place where socialization and education in group decision-making can occur. The school building's importance in educating students for creative work-lives is underscored by the fact that real creativity depends on hands-on learning experiences and interaction with a wide diversity of other people. Not only is the university classroom building not going away anytime soon, it should never go away and our aim should be to strike a careful balance between the learning that students can do alone, off-site, and that which requires non-virtual, real-world spaces.

\section{A Well-Lighted Place}

Daylight is the standard for lighting quality in educational environments. This means not only that natural daylight should be maximized but also that artificial lighting should emulate the attributes of daylight to the greatest extent possible with the use of "full-spectrum" fixtures. Studies have demonstrated a positive correlation between daylighting of interior spaces and academic performance. For example, a 1999 California Board for Energy Efficiency study, which tracked 21,000 students in three states, found that over a one-year period students in classrooms with the most daylight improved 20 percent faster on math tests and 26 percent faster on reading over those students in classrooms with the least amount of daylight. [4] Teachers, by the way, also perform better in naturally daylit environments.

The days of the harsh, fluorescent-lit college classroom are gone for good. Historically, classroom lighting levels have been determined by two significant factors: foot candles and cost. However, these criteria need to be re-examined based on the quality of light provided. Daylight, which contains a continuous spectrum of all light wavelengths, is the standard measure for color quality in lighting. By contrast, most fluorescent lighting gives off a discontinuous spectrum: a flickering light with spikes of color. Considering that it is free, daylight is an energy efficient source of illumination; maximizing daylight can have an extremely positive effect on a school's operating costs.

Designing for day-lighting can be a complicated undertaking. The penetration of direct sunlight into learning spaces is usually not desirable, for a number of reasons including the burden that the extra heat from direct sunlight can put on cooling loads and, of course, the glare that direct sun can cause. Controlling glare is especially important in spaces where computers are used, since reflected glare can bounce off computer screens into the eyes of the user. Some of the strategies commonly employed for maximizing daylight while minimizing glare are the use of 
full-spectrum filters, clerestory windows, skylights, and lightshelves. It is also a appropriate to limit the use of direct artificial lighting, especially in flexible spaces where furniture is likely to be reconfigured often and where the placement of computers is unpredictable. Indirect light provided by pendant fixtures is generally preferred, though there is a problem with indirect lighting, as well: its visual monotony. It is often advisable to counteract that monotony, and provide some visual relief, with task lighting and/or accent lighting at displays.

Designing for day-lighting involves paying attention to the overall orientation of a facility and the spaces within it. Generally speaking, a north-south orientation, with windows concentrated on the east- and west-facing walls of interior spaces is best, for it allows spaces throughout the facility to enjoy a shifting pattern of light throughout the day. By contrast, north- and southfacing windows receive more or less even amounts of light, too little or too much, respectively. A concern for compass orientation has waned in recent decades, with the development of heating and cooling systems that can effectively control interior climate conditions no matter how much or how little sunlight is entering a space. When the quality of light changes over the course of the day, however, the occupants of a space feel a greater connection to the outside world, and it is been shown that an awareness, even a subconscious awareness of that daily rhythm of changing light can, like daylight itself, be a boon to performance and creativity.

\section{Teachers Need Space, Too}

Designing a building to foster learning requires paying attention to the needs of teachers as well as those of students, since faculty creativity and professionalism are so essential to students' success. To develop creativity and improve professional standards, teachers need private spaces. Spaces where they can pursue individual work and common areas where they can meet with other faculty to discuss curriculum, students' progress, and professional matters, as well as relax and enjoy one another's company. Faculty development can take place in one, centralized location or a number of decentralized spaces dispersed throughout the facility. Individual faculty offices should also be large enough to accommodate private conferences.

\section{A Balanced, Welcoming Facility}

Before I conclude this paper, I need to mention two other aspects of good university design: overall balance and a sense of welcome. Spatial "balance" is a difficult idea to communicate verbally, since it has to do with how well the facility works as a whole, and from the perspective of those using it: Do the pieces fit together well? Are spaces sized appropriately? Are the spaces easy to make effective use of, and do they provide the right amount and kind of interplay with other spaces?

A well-balanced school building has already traveled a fair distance toward becoming a welcoming facility, one that invites users in to use it. By "users", I mean everyone who uses it: students first of all, but also teachers, administrative, staff, and other school-related visitors. One essential component of "a welcoming" design is visibility. A user should always be able to find his or her way from point A to point B with relative ease. This aspect of circulation (which architects refer to as wayfinding) can be enhanced through clear, easily intelligible signage that is placed just where people will need it. 
Another way of establishing a sense of welcome is to use design to celebrate the school and the academic community. To the greatest extent possible the facility should serve as a stage or backdrop for the students who are, after all, the central players of the school. Celebrating their achievements is made easier when there are plenty of places including walls, boards, and display cases to exhibit the students' work. The larger university community is celebrated when designers take care to ensure that the building "fits" into the campus. This means that the building design should somehow incorporate references to the university's life and history and it should visibly belong to its academic community.

\section{Conclusion}

University professors are generally creative, inventive, resourceful people. And when it comes to many university facilities, even some newer ones, it is a good thing that professors are as ingenious as they are. Professors often must teach "around" the architecture, which insists on getting in the way of the teaching and learning experience. At many American universities, the physical setting is unsuccessful, typically following the passive "egg crate" closed classroom format of years ago, and is often more like a prison than a place of exploration, discovery and creativity. School environments have a largely unrealized potential as active contributors to the teaching and learning process.

Quality school environments enhance, even improve, attitude and achievement, and a welldesigned school is one that carefully integrates the curriculum and the educational environment. At the foundation of this paper is the strong conviction that the physical environment has a direct impact on the educational process.

\section{References}

[1] Perkins, B. 2001. Building Type Basics for Elementary and Secondary Schools. New York, John Wiley \& Sons, p. xii.

[2] Ibid., p. xii.

[3] Cadwell, L. 1997. Bringing Reggio Emilia Home: An Innovative Approach to Early Childhood Education. New York; Teachers College Press, p. 93..

[4] Zemike, Kate. 2001. "The Feng Shui of Schools." New York Times (Educational Supplement). August 5, 2001.

\section{Daniel Davis}

Daniel Davis, AIA is an Associate Professor in the College of Engineering, Technology, and Architecture at the University of Hartford. He has more than 20 years of experience as a Design Architect and many of his projects have been published in professional journals and/or won design awards. He is also an Associate with FletcherThompson, Architects and Engineers and is the Director of Design of their Hartford, CT office. 